\title{
The implementation of a flipped classroom approach at a UK dental school
}

\author{
Rebecca S. L. Binnie*1 and Stephen J. Bonsor ${ }^{2}$
}

\section{Key points}

The flipped classroom (FC) approach has been fully implemented in the delivery of the application of dental materials and biomaterials teaching at a UK dental school.
The new approach met with significant, measurable student satisfaction feedback.
The FC approach can be adapted to asynchronous and synchronous sessions to meet the blended learning teaching approach which, as a result of the COVID-19 pandemic, is especially pertinent.

\begin{abstract}
Introduction The flipped classroom (FC) format involves the student reviewing the theoretical subject matter through material provided prior to a face-to-face teaching session. The intention is that because the student is familiar with the material, they will derive more from the tutor contact time. This format has been shown to increase student satisfaction, performance and cognitive development, and delivers better academic attainment.
\end{abstract}

Method The present paper describes the transition from a traditional lecture-based approach to a blended FC format in the delivery of the application of dental materials and biomaterials course at a UK dental school during the academic year 2019/2020, and compares student feedback before and after the transition.

Results The formal and informal feedback received from students after the change was entirely positive.

Discussion $\mathrm{FC}$ shows great promise as an andragogic tool in a clinical discipline, but further quantitative research is required, especially in respect to measuring academic attainment.

\section{Introduction}

In recent years, many new, exciting and novel teaching methods have been described and piloted, largely driven by advances in technology. One such novel andragogic technique has been termed the flipped classroom (FC). This approach involves the student reviewing the theoretical aspects of the course through material provided, often by pre-recorded lectures, before face-to-face teaching, the intention being that as the student is familiar with the subject matter, they will derive more from the tutor contact time. This format has been shown to increase student satisfaction, ${ }^{1}$ performance and cognitive development, ${ }^{2,3}$ and delivers better academic attainment. ${ }^{4,5}$ It was anticipated that utilising this new teaching method would improve student satisfaction with respect to the teaching of the applied dental materials and biomaterials $(\mathrm{ADM} \& \mathrm{~B})$ theme

${ }^{1}$ Clinical Lecturer, Institute of Dentistry, University of Aberdeen, UK; ${ }^{2}$ Senior Clinical Lecturer, Institute of Dentistry, University of Aberdeen, UK.

*Correspondence to: Rebecca Binnie

Email address: rebecca.binnie@abdn.ac.uk

Refereed Paper.

Accepted 21 October 2020

https://doi.org/10.1038/s41415-021-3125-6 at a UK dental school. The present study aims to assess student satisfaction with the course before and then after the theoretical teaching was flipped by means of measurement via the student course evaluation forms (SCEFs).

\section{Flipped classroom approach}

The FC approach often embraces the availability of computer technology to allow the removal of taught lectures from the timetable and their delivery online before teacher-facilitated conceptual application activities. ${ }^{6}$ It has evolved since its inception within a US secondary school to wide acceptance in tertiary education worldwide. ${ }^{6}$ The FC approach has seen success in various disciplines throughout medicine, ${ }^{1,7}$ and evidence of its use and success is emerging within dentistry. ${ }^{3,4,8,9}$ Although many of the positive findings report on student satisfaction, ${ }^{1,9}$ there is early evidence linking it with increased academic achievement. ${ }^{4,10,11}$ A recent meta-analysis of FC across a range of healthcare disciplines found that it yielded significant improvement in student learning in comparison to traditional approaches $^{12}$ and other studies in dental disciplines have shown that it better supports lower-performing students. ${ }^{13,14}$

\section{Andragogic rationale for the flipped classroom approach}

Challenges exist within dental teaching to accommodate the four recognised learning styles as described by Honey and Mumford, ${ }^{15}$ which have been inspired by Kolb's work. ${ }^{16}$ Table 1

Table 1 The four recognised learning styles and attributes, with an explanation on how each could be satisfied by using the FC approach

\begin{tabular}{|c|c|c|}
\hline Learning style $^{20}$ & Attributes ${ }^{21}$ & Met through \\
\hline Activists & Individuals who learn by doing & Hands-on experience with dental products \\
\hline Reflectors & $\begin{array}{l}\text { Individuals who learn by watching and } \\
\text { thinking over concepts }\end{array}$ & $\begin{array}{l}\text { Tutorial and hands-on elements reflecting } \\
\text { back to didactic teaching }\end{array}$ \\
\hline Theorists & $\begin{array}{l}\text { Individuals who like to understand the } \\
\text { theory behind the actions }\end{array}$ & Structured learning pattern \\
\hline Pragmatists & $\begin{array}{l}\text { Individuals who need to see the practical } \\
\text { application to the 'real world' }\end{array}$ & $\begin{array}{l}\text { Practical experience with immediately } \\
\text { relevant link from the didactic teaching }\end{array}$ \\
\hline
\end{tabular}


presents how the change in course delivery to a FC blended approach planned to address all of these learning styles. ${ }^{15}$

Additionally, it was hoped that this revised style of course would encourage higher-order thinking. Using Bloom's taxonomy ${ }^{17}$ as a framework, the online lectures aimed to impart knowledge, and the tutorials aimed to investigate and develop comprehension before the practical session progressed into application and analysis. Kolb's learning cycle ${ }^{18}$ is a recognised theory of experimental learning which is applicable to the application of dental materials teaching, particularly as it is a practical subject. This theory is based on the assumption that students learn through doing. In this case, practical experience of mixing and handling dental products enriches the teaching experience, deepens the understanding of the student and reinforces the application of the subject. The student was provided with workbooks for the hands-on element to support experiential learning as demonstrated in Kolb's cycle $^{18}$ (Fig. 1). In addition, interactive problembased learning seminars were added to the programme. These were added to gain deeper learning and encourage students' self-directed learning. ${ }^{19}$

Furthermore, it was anticipated that this FC blended approach would bridge the generational gap between teaching and learning styles..$^{20}$ Students are currently most likely to be part of 'generation Y'. This generation as a whole are highly collaborative, thrive using technology, respond to a mentoring/coaching form of teaching and favour case studies with immediate feedback, ${ }^{21}$ all of which is incorporated into the FC blended approach. ${ }^{11}$

\section{Materials and methods}

The School of Medicine Ethics Review board was contacted to determine whether an ethical opinion was required. Written confirmation was duly received confirming that the present study was considered to fall into the category of service evaluation and, as such, did not require ethical approval.

In order to facilitate the change to an FC approach, in this instance, it was deemed appropriate to overhaul the entire ADM\&B course. The proposed course was initially mapped or storyboarded ${ }^{22}$ by the academic theme lead responsible for the course dividing it into topics defined by their theme. Mini lectures called 'lecturettes' were adapted from the previously available didactic lecture material, recorded and saved as a PowerPoint (Microsoft Inc, Redmond,

\section{Fig. 1 Application of Kolb's learning cycle to the teaching of applied dental materials and biomaterials}

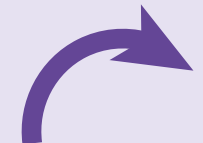

Active experimentation

Retesting conclusions to review material performance

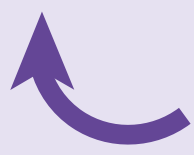

Concrete experience Working/experimenting with dental materials

\section{Relating conclusions back to the properties of the material}

Abstract conceptualisation

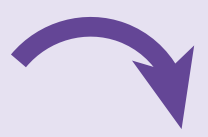

Reflective observation Respond to workbook questions related to the dental material

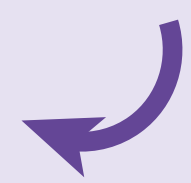

WA, USA) presentation relative to each theme. These tended to be short and thus made it easier for the student to concentrate and be less likely to lose interest. They also allowed the course to be made modular for versatility as some subject matter was covered in a number of areas. For example, common dental impression materials are used in the construction of removable dentures and also in fixed prosthodontics, which are covered in two other distinct courses. Each of the lecturettes covering the traditional lecture material were recorded as podcasts by video capture as this has been found to be more effective in knowledge retention ${ }^{23}$ using Panopto, Seattle, USA. These podcasts were made available on the university's virtual learning environment (VLE). The session was shown in the student's calendar with the presentation in PowerPoint (Microsoft Inc.) format attached with the link to the podcast. The students were encouraged to watch the podcast with the lecture presentation, which allowed them to annotate notes or write down any questions which sprung to mind at the time. Mandatory consolidative tutorials and hands-on practical sessions were timetabled after the lecture slides and podcasts had been made available. Expectations that the lectures should be viewed before attending the tutorial and practical sessions to get the most out of the session and to enable contribution were communicated to the students verbally by the course coordinator and were written in the course handbook.

The tutorials replaced the previous lectures in timetabled contact time and were held just before the practical sessions. They were facilitated by the lecturer who adapted the teaching to the direction the learning demanded. It also provided the opportunity of emphasising key points, sense-checking knowledge and understanding, allowing student-led discussion and facilitating question asking. This peer interaction has been shown to develop deeper conceptual understanding. ${ }^{11}$ Gali et al. ${ }^{24}$ found that tutorial-based discussion as opposed to traditional lecture-style teaching for dental materials helped students relate the teaching to clinical application. Students also reported finding the teaching more motivating and interesting. The tutorials sporadically included quizzes by means of OMBEA Response (OMBEA Ltd., London, UK). Research has shown that the testing effects of quizzes have a positive effect on learning outcomes, ${ }^{25}$ in addition to assessing the understanding of the theoretical material supplied before face-to-face teaching events. ${ }^{26}$

As was custom at the end of every semester, students were encouraged to provide formal feedback via the SCEF reports. The formal and informal feedback gained was compared with that received before the change in format of the theme.

\section{Results}

Due to the small cohort of students in each year group and a very limited number of staff who were involved in the delivery of the ADM\&B course at the Institute of Dentistry, University of Aberdeen, it was felt that direct quotations of student comments could not be included in the present paper to preserve and protect anonymity.

It was, however, observed that students' comments in the SCEFs largely fell into four main categories, namely: teaching delivery method, teaching time, accessibility to information and content.

Regarding teaching delivery method, prior to the change, more students commented that they were dissatisfied than satisfied. Following the change, four times the number of students commented that they were satisfied rather than 
being dissatisfied. All comments relating to the length of teaching time to deliver the teaching material moved from unanimously unsatisfied to satisfied. This was repeated in the students' response to the accessibility of the material. The content of the material largely did not change and students were always content with the information provided, but following the change, more students commented on the content positively.

There were significantly more comments from the students via the SCEF forms following the change to a FC blended learning approach than before the changes were made.

The original SCEF reports contained no numerical scores, but scores were introduced in the academic year 2019/20 in an attempt to measure approval and effectiveness of the course. Enjoyment of the course and teaching format effectiveness was judged on a fourpoint scale: strongly agreeing (SA), generally agreeing (GA), generally disagreeing (GD) and strongly disagreeing (SD). As can be seen in Figures 2 and 3, all students agreed that the course was enjoyable and effective, with only one BDS3 student who generally disagreed that the teaching format was effective.

\section{Discussion}

Due to the diversity of content and styles, finding evidence to support a change in course design is challenging and so is often left to professional judgement. ${ }^{2}$ However, of all the available andragogic approaches and emerging evidence of the effectiveness of FC within healthcare education, this method seemed the most appropriate for the course in question as, while previous student satisfaction was good with regards to relevance and content, it was low with respect to its delivery.

The success of the new FC format was measured in formal and informal feedback received from the students and compared with comments received from the previous format. As anticipated, students reported that they liked the FC format as they could access the online material and consume it at their own pace, as often as necessary and at a time which suited them. This was particularly useful for more complex ideas and concepts where the student could replay the section repeatedly until they understood it. Most students were fully engaged with the process and those who did, by definition, carried out more pre-class preparation time. This was borne out in a paper by Cheug. ${ }^{7}$ Furthermore, the results

\section{Fig. 2 Student SCEF results rating the enjoyment of the course (as a percentage)}

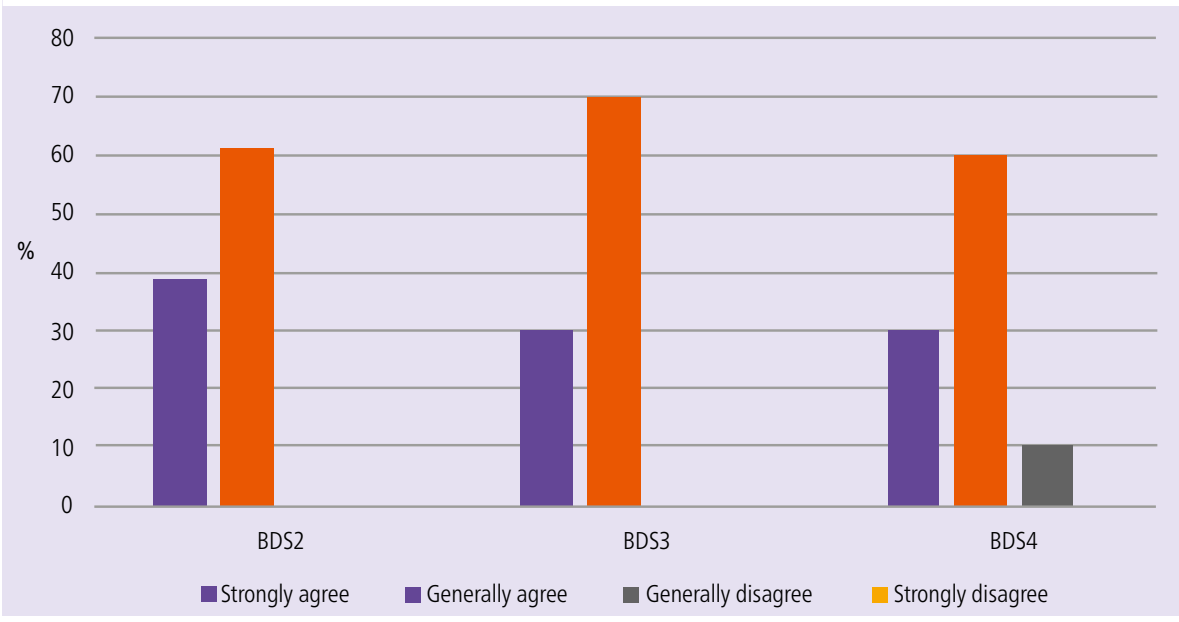

Fig. 3 Student SCEF results rating the teaching format effectiveness (as a percentage)

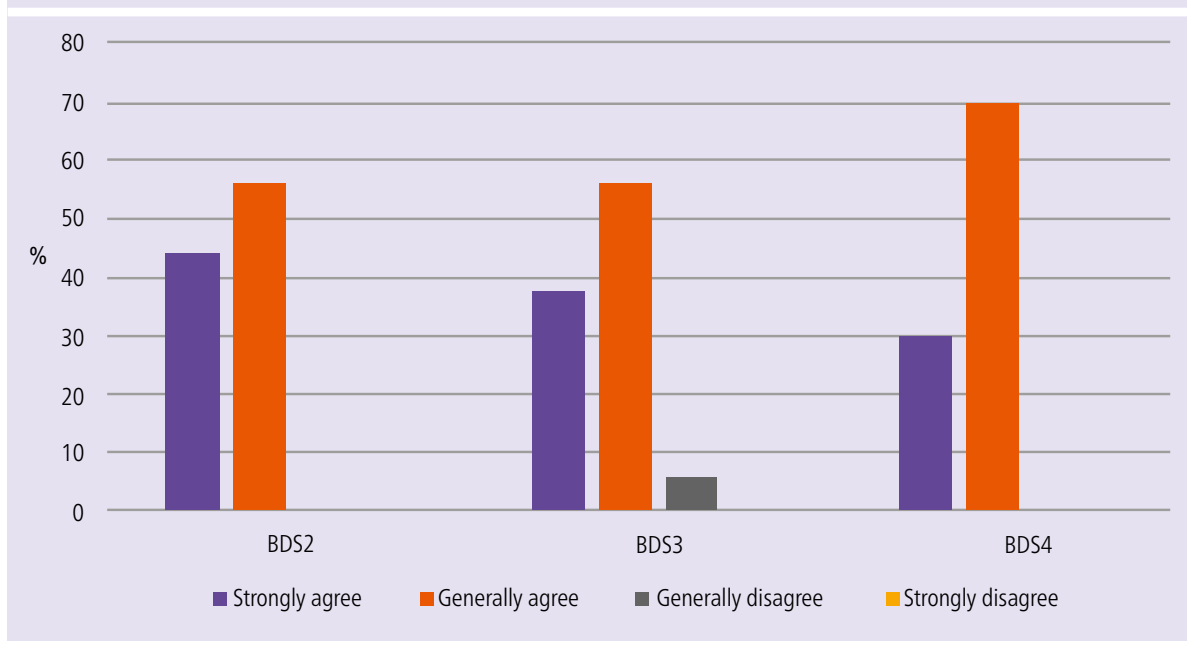

show that the students appreciated the more quality tutor/learn contact time and the fact that the pre-practical tutorials were dictated by their learning needs. As anticipated, this combination of tutorials and hands-on elements increased learner engagement, enjoyment and interaction.

The undergraduate dental teaching facility in Aberdeen was established relatively recently and quickly. At the time, many processes were developed for immediate implementation, but have been adapted and improved with usage to make them more fit for purpose. This was the case with the formal course feedback vehicle. The original SCEF forms asked for feedback on the curriculum overall and then, with time, were incrementally refined to asking about dental health and disease, the umbrella term under which the theme was contained, and then finally feedback was requested specifically for ADM\&B. Similarly, general comments were asked for in the initial reports, but progression led to more specific questions on strengths, weaknesses and any innovative teaching methods which had been used in the course delivery. Pertinent feedback on the delivery of the blended FC approach was entered into other disciplines. This was collated and included within the results. For the purposes of the present study, it is regrettable that numerical data were not collected from the outset as this would have led to meaningful measurement of improvement or otherwise of any changes effected within the course.

Like many universities, lectures are not deemed to be compulsory at the University of Aberdeen, even in a programme regulated by an external body, such as the General Dental Council, which has a legal and statutory duty to oversee dental education in the UK. All other classes are compulsory; therefore, by changing the session description to a tutorial, students were compelled to attend. This increase in attendance increased involvement, engagement and learning. 
It has been reported in the literature that there are potential difficulties with the FC format. The format of FC relies on the student to undertake preparation in advance of tutorials and often this is in their own time. Chuang et al. found that the FC approach did not suit all students as it required a high level of belief and motivation to complete the preparatory work. ${ }^{27}$ It could be hypothesised that students undertaking a professional degree in healthcare would be highly motivated, but Patanwala et al. ${ }^{28}$ found this not to be the case as some students studying pharmacy therapeutics failed to view the prerecorded material and thus were not prepared for the tutorials. However, it was found in this course that most students were engaged and prepared, and attended the face-to-face sessions with a good initial grasp of the subject. The authors deem this to be a result of clearly directing the students to the podcasts and lecture slides via the course handbook and VLE, while advising them that viewing was a prerequisite for the mandatory tutorials. The tutorial and practical sessions were also interactive and engaging, with the lecturer expecting student participation. Students quickly realised that failure to prepare would be apparent. If all courses were taught in such a way, however, then this could be problematic as the student may be overloaded and not have sufficient protected time to watch all of the lecture material. This preparatory, asynchronous material must be factored into the students' timetable.

To establish and embed the concept of FC into the delivery of the academic theme, there were challenges which had to be overcome. It is obvious that significant preparation time was required to record the podcasts. Additionally, there was a learning curve with the software and developing editing skills which was also time-consuming.

To flip the classroom resolved issues with maximising contact periods for a time-restricted lecturer and allowed exploration of a new teaching style. Interaction was more dynamic, making the learning environment more positive for both staff and students and reversing common assumptions that dental materials is a 'dry' subject. Members of staff at the Institute of Dentistry, University of Aberdeen had used the FC approach in isolated events with varying degrees of success, but it had yet to be embraced in the delivery of a whole course.

As with other delivery styles, there are challenges if the main facilitator is absent from the face-to-face session and therefore unable to conduct the tutorial, as the facilitator is key to the success of the FC approach. The knowledge of the educational facilitator needs to be at a sufficiently high level to be able to take the discussion in any direction and in sufficient depth, and for the students to see value in preparation and participation. The students take ownership of their learning, but the facilitator must be able to respond and accommodate.

The fact that the formal teaching material was pre-prepared meant that the course was ready to be delivered at any time. At the time of writing in the midst of the COVID-19 pandemic, this approach enabled the course to be delivered online and facilitated the move for staff to work from home as the core of the teaching was in place. The students therefore saw no interruption of the theoretical teaching as online live tutorials were provided as an acceptable replacement of the face-to-face sessions. Furthermore, the material is available for future cohorts. Material will continue to need updating from time to time, but there will be a saving in lecturer time which will result in overall cost savings balanced by the initial start-up costs of the investment of time.

\section{Conclusion}

The change to an FC delivery from a traditional lecture-based programme resulted in unanimously positive student feedback measured in both formal and informal feedback. This was consistent with other previously published findings. Further investigation is needed to see if improvement in summative assessments would be achieved by adopting an FC approach.

\section{Acknowledgements}

No financial support was received to produce this paper.

\section{Author contributions}

Both authors contributed equally to every stage in the production of this paper.

\section{Ethics declaration}

The authors declare no conflicts of interest.

\section{References}

1. Morgan H, McLean K, Chapman C et al. The flipped classroom for medical students. Clin Teach 2015; 12: 155.

2. Swanwick T. Understanding medical education: Evidence, theory and practice. 2nd ed. Chichester: Wiley Blackwell, 2014.

3. Kohli S, Sukumar A K, Zhen C T et al. Dental education: Lecture versus flipped and spaced learning. Dent Res J (Isfahan) 2019; 16: 289-297.
4. Qutieshat A S, Abusamak M O, Maragha T N. Impact of Blended Learning on Dental Students' Performance and Satisfaction in Clinical Education. J Dent Educ 2020 84: 135-142.

5. Hafferty FW. Beyond curriculum reform: Confronting medicine's hidden curriculum. Acad Med 1998; 73: 403-407.

6. Jensen J L, Kummer T A, Godoy P D d M. Improvements from a Flipped Classroom May Simply Be the Fruits of Active Learning. CBE Life Sci Educ 2015; DOI: 10.1187/ cbe.14-08-0129.

7. Cheng X, Ka Ho Lee K, Chang E Y, Yang X. The "flipped classroom" approach: Stimulating positive learning attitudes and improving mastery of histology among medical students. Anat Sci Educ 2017; 10: 317-327.

8. Crothers A, Bagg J, McKerlie R. The Flipped Classroom for pre-clinical dental skills teaching - a reflective commentary. Br Dent J 2017; 222: 709-713.

9. Lee C, Kim S. Effectiveness of a Flipped Classroom in Learning Periodontal Diagnosis and Treatment Planning. J Dent Educ 2018; 82: 614-620.

10. Zhu L, Lian Z, Engstrom M. Use of a flipped classroom in ophthalmology courses for nursing, dental and medical students: A quasi-experimental study using a mixedmethods approach. Nurse Educ Today 2020; 85: 104262

11. Gillispie V. Using the Flipped Classroom to Bridge the Gap to Generation Y. Ochsner J 2016; 16: 32-36.

12. Hew K F, Lo C K. Flipped classroom improves student learning in health professions education: a metaanalysis. BMC Med Educ 2018; 18: 38.

13. Sergis S, Sampson D G, Pelliccione L. Investigating the impact of flipped classroom on students' learning experiences: A self-determination theory approach. Comput Human Behav 2018; 78: 368-378.

14. Alcota M, Muñoz A, González F E. Diverse and participative learning methodologies: A remedial teaching intervention for low marks dental students in Chile. J Dent Educ 2011; 75: 1390-1395.

15. Honey, P, Mumford. A. Manual of Learning Styles. London: Honey, 1982.

16. Leaver B, Ehrman M, Shekhtman B. Learning styles and learning strategies. In Achieving Success in Second Language Acquisition. pp 65-91. Cambridge: Cambridge University Press, 2005.

17. Bloom B S. Taxonomy of educational objectives Handbook I: Cognitive domain. New York: McKay, 1969.

18. Kolb D A. Experiential Learning: Experience as the Source of Learning and Development. Englewood Cliffs, NJ: Prentice Hall, 1984.

19. Biggs J. What the Student Does: teaching for enhanced learning. Higher Educ Res Dev 1999; 18: 57-75.

20. Dictionary.com. Generation. Available at http:// dictionary.reference.com/browse/generation (accessed August 2015).

21. Moreno-Walton $L$, Brunett $P$, Akhtar S, DeBlieux $P$ $M$. Teaching across the generation gap: a consensus from the Council of Emergency Medicine Residency Directors 2009 academic assembly. Acad Emerg Med 2009; 16: 19-24.

22. Salmon G, Greogory J, Lokuge Dona K, Ross B. Experiential Online Development for Educators: The Example of the Carpe Diem MOOC. Br J Educ Technol 2015; 46: 542-556.

23. Dey E L, Burn HE, Gerdes D. Bringing the Classroom to the Web: Effects of Using New Technologies to Capture and Deliver Lectures. Res High Educ 2009; 50: 377-393.

24. Gali S, Shetty V, Murthy N S, Marimuthu P. Bridging the gap in 1 (st) year dental material curriculum: A 3 year randomized cross over trial. J Indian Prosthodont Soc 2015; 15: 244-249.

25. Spanjers $\mid A$ E, Könings K D, Leppink J et al. The promised land of blended learning: Quizzes as a moderator. Educ Res Rev 2015; 15: 9-74.

26. DeLozier S J, Rhodes M G. Flipped Classrooms: a Review of Key Ideas and Recommendations for Practice. Educ Psychol Rev 2017; 29: 141-151.

27. Chuang $H$, Weng CY, Chen C H. Which students benefit most from a flipped classroom approach to language learning? Br J Educ Technol 2018; 49: 56-68.

28. Patanwala A E, Erstad L, Murphy J E. Students use of flipped classroom videos in a therapeutics course. Curr Pharm Teach Learn 2017; 9: 50-54. 